\title{
Synthesis of Xanthene Derivatives using Template-containing Zn/MCM-41 as a Green and Reusable Catalyst; Effect of the Template
}

\author{
Mahtab Pirouzmand, ${ }^{1, *}$ Adel Mahmoudi Gharehbaba ${ }^{1}$ and Zarrin Ghasemi ${ }^{2}$ \\ 1 Department of Inorganic chemistry, Faculty of chemistry, University of Tabriz, Tabriz 5166616471, Iran \\ 2 Department of Organic and Biochemistry, Faculty of Chemistry, University of Tabriz, Tabriz 5166616471, Iran \\ * Email: m.pirouzmand@tabrizu.ac.ir (M. Pirouzmand)
}

Received March 23, 2016; Accepted August 25, 2016.

\begin{abstract}
Two approaches for metal ion incorporation were employed to introduce Zn into MCM-41; Direct Synthesis (DS) and Wet Impregnation (WI). The ionic template was removed by two different methods: calcination and solvent extraction. For comparison, a series of template-containing mesoporous $\mathrm{Zn} / \mathrm{MCM}-41$ was also synthesized without surfactant removal. The catalysts were examined in a three component reaction to afford benzoxanthene derivative. The templae-containing $\mathrm{Zn} / \mathrm{MCM}-41$ showed particularly the highest activity. This activity is due to both Lewis acid sites and the ionic template. This catalyst could be reused without loss of its catalytic activity because the organic template does not leach during the reaction. It is also very efficient for the synthesis of a hydroxanthene derivative.

Keywords: Ionic template; Zn/MCM-41; Solid acid catalyst; Xanthene; Solvent free.
\end{abstract}

\section{Introduction}

Xanthenes and benzoxanthenes are an important class of organic compounds. Xanthenes and its derivatives are important in the area of medicinal chemistry. They have various pharmacological activities such as antibacterial [1], antiviral [2] and anti-inflammatory properties [3]. Furthermore, they have been utilized as antagonists for drug-resistant leukemia lines [4] and in photodynamic therapy [5]. They are also applied as dyes in laser technology [6] and as $\mathrm{pH}$ sensitive fluorescent materials for visualization of biomolecules [7].

For the construction of xanthenes and benzoxanthenes, various procedures are available including the cycloacylation of carbamates [8], cyclocondensation between 2-hydroxy aromatic aldehydes and 2-tetralone [9], cyclodehydrations [10] and intramolecular phenyl carbonyl reaction of aldehydes with $\beta$-naphthol [11]. However, these methods suffer from certain drawbacks including long reaction times, and using poisonous and expensive catalyst materials. Some of the catalysts are destroyed in the work-up procedure and cannot be recovered or reused. Therefore, the search continues for a better catalyst to synthesize of benzoxanthenes in terms of operational simplicity, reusability of catalyst, low cost, and greater selectivity.

Recently, mesoporous molecular sieves (like MCM-41 and MCM-48), have attracted much interest in catalysis, due to their high surface area, well defined pore shape, narrow pore size
Resumen. Para introducir Zn en MCM-41 se utilizaron dos estrategias: la síntesis directa (DS) y la impregnación húmeda (WI). Se sintetizaron series de materiales $\mathrm{Zn} / \mathrm{MCM}-41$ con plantilla y sin ella. En algunos sólidos la plantilla se eliminó ya sea por calcinación o por extracción por solventes. Los sólidos se examinaron en la reacción de tres componentes para obtener los bensoxantenos. El catalizador con plantilla mostró la mayor actividad, que se explica en términos de la presencia tnato de sitios ácidos de Lewis como de la plantilla iónica. Este catalizador se volvió a utilizar sin pérdida en la actividad catalítica debido a que la plantilla no se lixivia durante la reacción. También se encontró que este catalizador es útil para la síntesis de derivados hidroxantenos.

Palabras clave: plantilla iónica; Zn/MCM-41; catalizador sólido ácido, xanteno, libre de solvente.

distribution, and good thermal stability. These are particularly attractive for heterogeneous reactions of large organic molecules for which microporous zeolites cannot be used. These mesoporous material are prepared by using ionic surfactants [12]. Generally, the residual template inside the pores is removed by calcination or extraction. As ionic surfactants contain an organic cation such as cetyltrimethylammonium $\left(\mathrm{C}_{19} \mathrm{H}_{42} \mathrm{~N}^{+}\right)$and an inorganic anion, we hypothesized that they could act as an ionic liquid. Herein, we report the preparation of two xanthene derivatives in the presence of template-containing $\mathrm{Zn} / \mathrm{MCM}-41$ as heterogeneous catalyst under solvent free conditions.

\section{Results and discussion}

The low angle XRD patterns of MCM-41 exhibit four well-resolved peaks with a very intense diffraction peak $(100)$ at $2 \theta$ $\approx 2.5$ and three peaks with lower intensity at ca. $3-5^{\circ}$ which were indexed to the 110,200 , and 210 planes characteristic for textural uniformity of the hexagonal p6mm structure [13]. All $\mathrm{Zn} /$ MCM-41 samples show a typical peak about $2 \theta=2.2^{\circ}$, the characteristic peak of MCM-41, indicating that the ordered mesoporous structure of parent MCM-41 was preserved after the introduction of zinc ions (Fig. 1). However the catalyst prepared by the WI method does not have long-range crystalline order because the reflections due to higher indices became weak. 


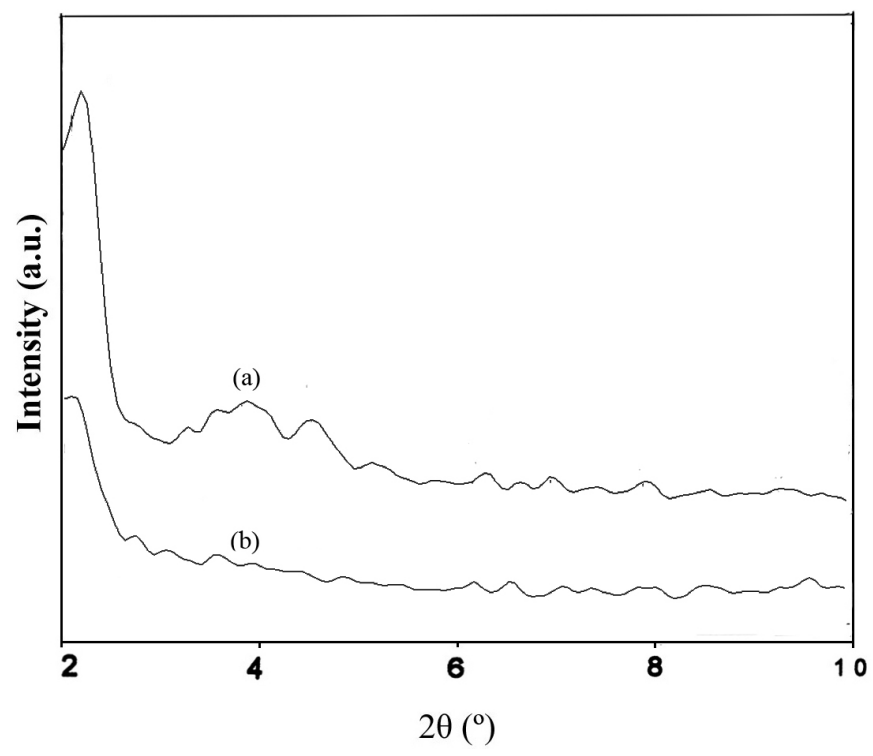

Fig. 1. X-ray powder diffraction of a) $\mathrm{Zn} / \mathrm{MCM}-41$ (DS) and b) $\mathrm{Zn} /$ MCM-41 (WI).

The elemental concentration distribution on the catalyst is reported in Table 1. EDX results showed that using the WI method high metal loading can be attained, because there is no intermediate washing step involved in wet impregnation approach, in contrast to the direct synthesis procedure. Furthermore the solvent extraction method decreases the metal loading because during this process, the zinc ions leach out of the support.

\subsection{Template removal}

In general, the template molecules are burned off by calcination at $500-600^{\circ} \mathrm{C}$ in air or oxygen. An alternative method for template removal is to extract it with hot conventional solvent. In this work, the organic template molecule was removed from the silicate lattice with these two techniques.

The removal of the template from as-synthesized MCM-41 was confirmed by Infrared spectrophotometry. Fig. 2 shows the FTIR spectra of template-containing Zn/MCM-41, solvent extracted and calcined $\mathrm{Zn} / \mathrm{MCM}-41$ samples. The [CTA]Zn/ MCM-41 sample exhibits absorption bands around $2970 \mathrm{~cm}^{-1}$, corresponding to $\mathrm{C}-\mathrm{H}$ stretch vibrations of the surfactant molecules. Two weak peaks in this region are also observed in the spectrum of solvent extracted $\mathrm{Zn} / \mathrm{MCM}-41$ samples. This was

Table 1. The amount of zinc of $\mathrm{Zn} / \mathrm{MCM}-41$ catalysts.

\begin{tabular}{ccc}
\hline & Catalysts & $\mathrm{Zn} *(\mathrm{Wt} \%)$ \\
\hline 1 & [CTA] Zn/MCM-41 DS & 3.32 \\
2 & Extracted Zn/MCM-41 DS & 0.94 \\
3 & Calcined Zn/MCM-41 DS & 3.49 \\
4 & Zn/MCM-41 WI & 4.66 \\
\hline
\end{tabular}

* determined by EDX analysis.

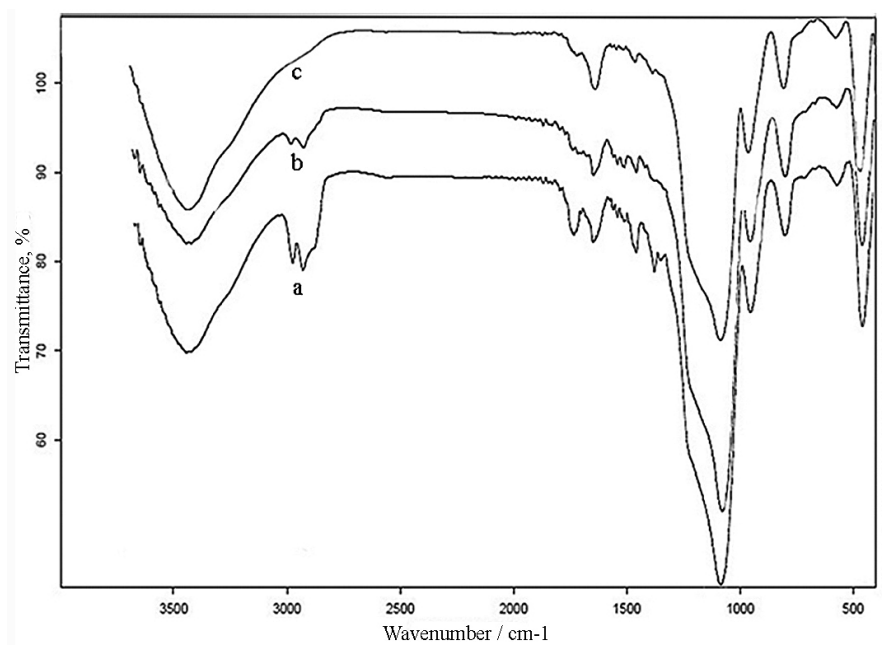

Fig. 2. FT-IR spectrum of a) [CTA] Zn/MCM-41 , b) Ethanol extracted $\mathrm{Zn} / \mathrm{MCM}-41$, c) Calcined $\mathrm{Zn} / \mathrm{MCM}-41$ prepared by direct synthesis.

probably caused by the incomplete extraction of the template. While the traditional calcination method fully eliminates the template, solvent extraction always leaves some traces of surfactant.

In our previous work, TGA analysis was also employed to determine quantitatively the amount of surfactant [14]. The amount of template was estimated from the weight loss between 150 and $450^{\circ} \mathrm{C}$. These amounts were approximately $25 \%, 5 \%$ and lower than $0.5 \%$ for template-containing, extracted, and calcinated $\mathrm{Ca} / \mathrm{MCM}-41$, respectively. These data also confirmed that most of the template molecules had been released via calcination.

\subsection{Synthesis of xanthene derivatives}

There are many reports for the synthesis of xanthene derivatives. The highest yield has been obtained by an ionic liquid as catalyst $[15,16]$. However there are certain concerns over the use of ionic liquids as green solvents because large amounts of organic solvent and energy are used in their preparation [17]. As we believed that the ionic surfactant could act as an ionic liquid, we compare the catalytic activity of template-containing and free template $\mathrm{Zn} / \mathrm{MCM}-41$ catalysts in a one-pot multicomponent condensation. Table 2 shows the catalytic performance of prepared catalysts in the reaction between benzaldehyde and $\beta$-naphtol in the presence of dimedone. It was expected that the reaction yield would increase with the zinc content of the catalyst, in accordance with an increase in the concentration of Lewis acidic centers. Furthermore, compared to calcined catalyst and catalyst prepared by wet impregnation, the template-containing Zn/MCM-41 exhibits superior catalytic activity in terms of yield ( $82 \%$ ), and reaction time (Table 1, entry $1,3,4)$. Actually, the cationic surfactant CTAB accelerated the model reaction to afford the desired product in good yield. The higher activity of extracted $\mathrm{Zn} / \mathrm{MCM}-41$ with very low zinc content, than the corresponding calcined form, confirmed this 
Table 2. Synthesis of compound 1 using Zn incorporated MCM-41 catalysts $^{\mathrm{a}}$

\begin{tabular}{|c|c|c|c|}
\hline Entry & Catalyst & $\begin{array}{l}\text { Time } \\
(\mathrm{min})\end{array}$ & $\begin{array}{l}\text { Yield } \\
(\%)^{\mathrm{b}}\end{array}$ \\
\hline 1 & [CTA]Zn/MCM41 DS & 30 & 82 \\
\hline 2 & Extracted Zn/MCM-41 DS & 40 & 76 \\
\hline 3 & Calcined Zn/MCM-41 DS & 45 & 53 \\
\hline 4 & $\mathrm{Zn} / \mathrm{MCM}-41 \mathrm{WI}$ & 52 & 42 \\
\hline 5 & [CTA]MCM-41 & 45 & 73 \\
\hline 6 & Calcined MCM-41 & 45 & 71 \\
\hline
\end{tabular}

${ }^{a}$ Reaction condition: dimedone $(1 \mathrm{mmol}), \beta$-naphtol ( $\left.1 \mathrm{mmol}\right)$ and benzaldehyde $(1 \mathrm{mmol}) ; 0.1$ gr catalyst

${ }^{\mathrm{b}}$ Isolated yield

effect (entry $2 \& 3$ ), because extracted catalyst still contained a low amount of the template. On the other hand, metal free [CTA]MCM-41 showed lower activity in comparison to [CTA] $\mathrm{Zn} / \mathrm{MCM}-41$. It can be concluded that ionic surfactant intensifies the effect of Lewis acid sites.

To prove the complementary effect of ionic surfactant, the catalytic activity of prepared $\mathrm{Zn} / \mathrm{MCM}-41$ catalysts was also evaluated in the synthesis of a hydrobenzene derivative from dimedone and benzaldehyde (Table 3). Interestingly, template-containing $\mathrm{Zn} / \mathrm{MCM}-41$ exhibited high catalytic activity for the synthesis of 3,3,6,6-tetramethyl-9-phenyl-1,8-dioxooctahydro xanthene (entry 1 ).

Ionic surfactant enhances the rate of this kind of reactions because the charged intermediates are present. Moreover it

Table 3. Synthesis of compound 2 using $\mathrm{Zn}$ incorporated MCM-41 catalysts $^{\text {a }}$

\begin{tabular}{cccc} 
Catalyst & $\begin{array}{c}\text { Time } \\
(\text { min })\end{array}$ & $\begin{array}{c}\text { Yield } \\
(\%)^{\mathrm{b}}\end{array}$ \\
\hline 1 & [CTA]Zn/MCM-41 DS & 25 & 92 \\
2 & Extracted Zn/MCM-41DS & 35 & 84 \\
3 & Calcined Zn/MCM-41 DS & 40 & 69 \\
4 & Zn/MCM-41WI & 45 & 60 \\
5 & [CTA]MCM-41 & 30 & 73 \\
6 & Calcined MCM-41 & 40 & 82 \\
\hline
\end{tabular}

${ }^{\mathrm{a}}$ Reaction condition: dimedone $(2 \mathrm{mmol})$ and benzaldehyde $(1 \mathrm{mmol})$; 0.1 gr catalyst

${ }^{\mathrm{b}}$ Isolated yield increases effective collisions between reactants. Generally, ionic surfactants in hydrophobic substrates can self-assemble reverse clusters, which provide a large interface between the catalyst and reactant where the reaction takes place, so greatly enhancing the reaction rate [18]. Also, the formation of CTAB cluster would congregate catalytic species $\mathrm{Zn}^{2+}$ at the reaction interface, which could catalyze the reaction more efficiently.

\subsection{Reusability of catalyst}

One of the most important features of a solid catalyst is the ability to be recycled. The template-containing $\mathrm{Zn} / \mathrm{MCM}-41$ synthesized via direct approach ([CTA]Zn/MCM-41 DS) that displayed the best catalytic activity was studied further. After the first test, the used catalyst was filtered, washed with ethyl acetate to remove any unreacted precursor and organic products. Then the recovered catalyst was charged for the next run. Recyclability of the catalyst was assessed by using it for 5 cycles (Table 4).

EDX analysis was performed to estimate the $\mathrm{Zn}$ content of the recovered catalyst after first and fifth run showing the presence of $\mathrm{Zn}$ atomic 3.09 and 2.86 respectively. This indicates that negligible leaching of the zinc from this support occurs under the reaction condition. So it has substantial stability under the used experimental conditions. Furthermore, XRD patterns of recovered $\mathrm{Zn} / \mathrm{MCM}-41$ catalysts showed the arrangement of mesoporous structure of MCM-41 was retained after reaction (see supplementary data, Fig. S5).

To determine the amount of organic template (CTA) that remained in the pores of the recovered [CTA]Zn/MCM-41, a thermogravimetric analysis experiment was performed. The TG curve of the as-synthesized $\mathrm{Zn} / \mathrm{MCM}-41 \mathrm{DS}$ is shown in Fig. 3a. Three distinct stages of weight loss were observed in template-containing $\mathrm{Zn} / \mathrm{MCM}-41$, weight loss below $150{ }^{\circ} \mathrm{C}$ (due to desorption of water), between $200-450{ }^{\circ} \mathrm{C}$ (due to decomposition of the template) and above $450{ }^{\circ} \mathrm{C}$ (due to water loss via condensation of silanol groups to form siloxane bonds). Weight loss of about $22 \%$ at temperatures between $200-450{ }^{\circ} \mathrm{C}$ was observed. This amount was approximately $21 \%$ for [CTA] $\mathrm{Zn} / \mathrm{MCM}-41$ after fifth run (Fig. 3b). So despite a weak interaction of CTA cations with siloxy anions, they are not continuously leached because they are stabilized in the micelles as a consequence of a strong interaction of the non-polar tails $[19,20]$. Therefore, [CTA]Zn/MCM-41 was found to be a reusable catalyst, which is one of the main requirements for employing this catalyst for the production of xanthenes derivatives.

Table 4. Reusability of [CTA]Zn/MCM-41 catalyst in synthesis of compound 1and $\mathbf{2}$

\begin{tabular}{lccccc}
\hline & \multicolumn{5}{c}{ Run } \\
\cline { 2 - 6 } & 1 & 2 & 3 & 4 & 5 \\
\hline Compound 1 Yield (\%) & 82 & 79 & 79 & 78 & 77 \\
Compound 2 Yield (\%) & 92 & 92 & 91 & 89 & 87 \\
\hline
\end{tabular}




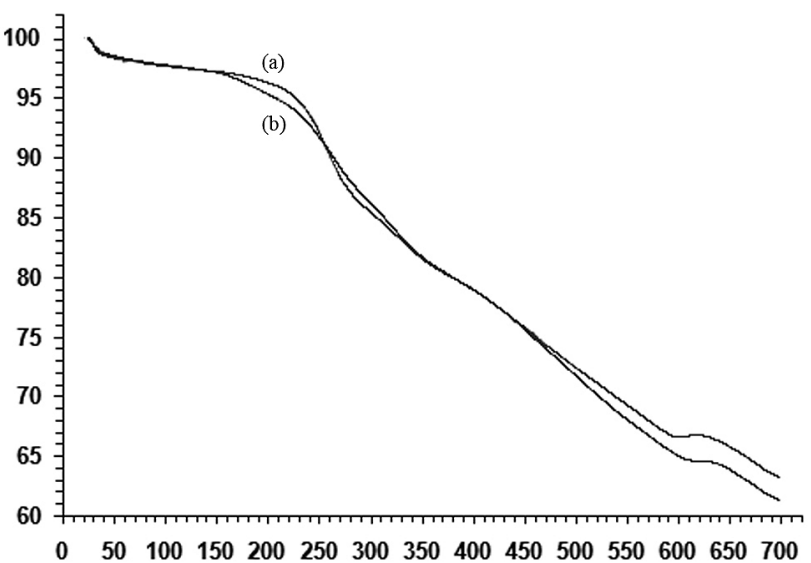

Fig. 3. TGA profile of a) $[\mathrm{CTA}] \mathrm{Zn} / \mathrm{MCM}-41 \mathrm{DS}, \mathrm{b})$ after 5 th run.

\section{Conclusions}

Zn/MCM-41 catalysts have been synthesized by direct synthesis and wet impregnation methods. Then the ionic template was removed by two different methods: solvent extraction and calcination. The prepared samples were used as catalyst in the synthesis of two xanthene derivatives. The results showed that template-containing $\mathrm{Zn} / \mathrm{MCM}-41$, prepared by direct synthesis approach, was the most active catalyst for this reaction, which could be attributed to the Lewis acid sites and ionic template effect. This catalyst was reused without significant loss of activity. Since there is no need to remove the template, this strategy saves energy and time and it also reduces the pollutants released to the environment. Furthermore, this catalyst is synthesized by a one-pot approach via a non-hydrothermally simple method and is cost effective.

\section{Experimental Section}

Cetyltrimethylammonium bromide (CTAB) was purchased from Sigma-Aldrich Inc. and the other reagents were purchased from Merck Company.

\section{Catalyst preparation}

-Direct SynthesisMethod (DS)

Zn/MCM-41 samples were synthesized according to standard literature procedure [21]. In a typical non-hydrothermal synthesis, $2.74 \mathrm{mmol}$ of CTAB were dissolved in $480 \mathrm{~mL}$ of $\mathrm{NaOH}$ aqueous solution $(15.0 \mathrm{mM})$, followed by a drop wise addition of $22.4 \mathrm{mmol}$ of tetraethylorthosilicate (TEOS). Then, a solid powder of zinc nitrate $(0.18 \mathrm{~g})$ was slowly added. The mixture was vigorously stirred and heated to $80^{\circ} \mathrm{C}$ for $2 \mathrm{~h}$. Subsequently, the product powder was isolated by hot filtration, washed with deionized water and dried in air $\left(\right.$ at $\left.25^{\circ} \mathrm{C}\right)$.

In some preparations the cationic surfactant was removed either by hot solvent extraction or by calcination in air at $640^{\circ} \mathrm{C}$ for $6 \mathrm{~h}$. The solvent extraction was performed by stirring $1 \mathrm{~g}$ of the air-dried product with a $1 \mathrm{M} \mathrm{HCl}$ solution in ethanol (liquid: solid $300 \mathrm{~mL} / \mathrm{g}$ ) at $333 \mathrm{~K}$ for $24 \mathrm{~h}$. Then the mesoporous material was collected by filtration and dried at room temperature. In order to compare the effect of the template, a series of as-synthesized molecular sieves, containing their organic template, were also tested for benzoxanthene synthesis without further modification.

\section{-Wet Impregnation Method (WI)}

The calcined MCM-41 sample was introduced into a calculated amount of $\mathrm{Zn}\left(\mathrm{NO}_{3}\right)_{3} \cdot 6 \mathrm{H}_{2} \mathrm{O}$ aqueous solution $(0.18 \mathrm{~g})$. After $3 \mathrm{~h}$, the resultant mixture was dried at $60{ }^{\circ} \mathrm{C}$.

\section{Catalyst characterization}

XRD measurements were performed on a Philips-PW 17C diffractometer with $\mathrm{Cu} \mathrm{K}$ radiation over the $2 \theta$ range $1-10^{\circ}$. The elemental chemical compositions of the samples were determined by EDX (VEGA \TESCAN-LMU, Czech Republic) under vacuum mode for precise measurement of both light and heavy elements. FTIR spectra were recorded on a Bruker Tensor 27 instrument using $\mathrm{KBr}$ pressed powder discs. A Mettler Toledo thermogravimetry (TG/SDTA 851) was used for thermogravimetric analysis (TGA). About $10 \mathrm{mg}$ of the sample was heated at $10{ }^{\circ} \mathrm{C} / \mathrm{min}$ up to $700{ }^{\circ} \mathrm{C}$ in air flow $(100 \mathrm{ml} / \mathrm{min})$.

\section{Synthesis of 12-phenyl-9,9-dimethyl-8,9,10,12- tetrahydrobenzo[a]xanthene-11-ones (Compound 1)}

A mixture of $\beta$-naphthol (0.144 g, $1 \mathrm{mmol})$, dimedone $(0.140 \mathrm{~g}$, $1 \mathrm{mmol})$, benzaldehyde ( $1 \mathrm{ml}, 1 \mathrm{mmol})$ and $\mathrm{Zn} / \mathrm{MCM}-41(0.1$ gr), was stirred in an oil-bath $\left(110^{\circ} \mathrm{C}\right)$ [22]. After completion of the reaction, as monitored by $\mathrm{TLC}$, the reaction mixture was cooled to room temperature; ethyl acetate $(15 \mathrm{~mL})$ was added to it, and stirred for $10 \mathrm{~min}$. Then the catalyst was separated by filtration. Finally, ethyl acetate was evaporated under vacuum to give the crude product. The crude product was recrystallized from $\mathrm{EtOH}$ to yield pure xanthenes-11-one derivatives.

All pure products were characterized by comparison of their physical (melting point) and spectral data $\left({ }^{1} \mathrm{H}\right.$ NMR) with authentic samples (supplementary information).

\section{Synthesis of 9-phenyl-3,3,6,6-tetramethyl-1,8-dioxo- octahydroxanthene (Compound 2)}

This xanthene derivative was synthesized by the above mentioned procedure with $2 \mathrm{mmol}$ dimedone without introducing $\beta$-naphthol.

\section{Acknowlegdement}

The authors thank Research Affairs of University of Tabriz for financial support. 


\section{References}

1. Omolo, J. J.; Johnson, M. M.; Van Vuuren, S. F.; de Koning, C. B. Bioorg. Med. Chem. Lett. 2011, 21, 7085-7088.

2. Jamison, J. M.; Krabill, K.; Hatwalkar, A.; Jamison, E.; Tsai C. C. Cell Biol. Int. Rep. 1990, 14, 1075-1084.

3. Poupelin, J. P.; Saint-Ruf, G.; Foussard-Blanpin, O.; Marcisse, G.; Uchida-Ernouf, G.; Lacroix, R. Eur. J. Med. Chem. 1978, 13, 67-71.

4. Nguyen, H. T.; Lallemand, M. C.; Boutefnouchet, S.; Michel, S.; Tillequin, F. J. Nat. Prod. 2009, 72, 527-539.

5. Carreon, J. R.; Roberts, M. A.; Wittenhagen, L. M.; Kelley, S. O. Org Lett. 2005, 7, 99-102.

6. Britt, A. D. ; Moniz, W. B. J. Org. Chem., 1973, 38, 1057-1059.

7. Knight, C.G.; Stephens, D. Biochem. J. 1989, 258, 683-687.

8. Quintas, D.; Garcia, A.; Dominguez, D. ChemInform, 2004, 35, 154-160.

9. Jha, A.; Beal, J. Tetrahedron Lett., 2004, 45, 8999-9001.

10. Sarma, R. J.; Baruah, J. B. Dyes Pigm., 2005, 64, 91-92.

11. Khoramabadizad, A.; Kazemi, Z.; Amin Rudbari, H. J. Korean Chem. Soc. 2002, 46, 541-544.

12. Beck, J. S.; Vartuli, J. C.; Roth, W. J.; Leonowicz, M. E.; Kresge, C. T.; Schmitt, K. D.; Chu, C. T. W.; Olson, D. H.; Sheppard, E. W.; McCullen, S. B.; Higgins, J. B.; Schlenker, J. L. J. Am. Chem. Soc., 1992, 114, 10834-10843.
13. Kresge, C. T.; Leonowicz, M. E., Roth, W. J.; Vartuli, J. C.; Beck, J. S. Nature 1992, 359, 710-712.

14. Pirouzmand, M.; Nikzad-kojanag, B.; Seyed-Rasulzade, S. K. Catal. Commun., 2015, 69, 196-201.

15. Shirini, F.; Yahyazadeh, A.; Mohammadi, K. Chin. Chem. Lett. 2014, 25, 341-347.

16. Zolfigol, M.A.; Khakyzadeh, V.; Moosavi-Zare, A.R.; Zare, A.; Azimi, S.B.; Asgari, Z.; Hasaninejad, A. C. R. Chimie 2012, 15, 719-736.

17. Deetlefs M; Seddon K.R. Green Chem. 2010, 12, 17-30.

18. Shinde, P.V.; Kategaonkar, A.H.; Shingate, B.B.; Shingare, M.S. Beilstein J. Org. Chem. 2011, 7, 53-58.

19. Martins, L.; Bonagamba, T.J.; Azevedo, E.R.; Bargiela, P.; Cardoso, D. Appl. Catal. A Gen. 2006, 312, 77-85.

20. Martins, L.; Cardoso, D. Micropor. Mesopor. Mater. 2007, 106, 8-16.

21. Tantirungrotechai, J.; Thananupappaisal, P.; Yoosuk, B.; Viriya-empikul, N.; Faungnawakij, K. Catal. Commun. 2011, 16, 25-29.

22. Habibi , D.; Kaamyabi, S.; Hazarkhani, H. Chin. J. Catal. 2015, 36, 362-366. 